\title{
MULTI-SOURCE SATELLITE OBSERVATIONS REVEAL EVOLUTION PATTERN OF RIFTS IN THE FILCHNER-RONNE ICE SHELF, ANTARCTICA
}

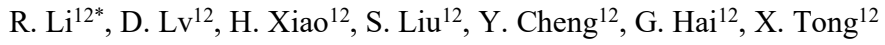 \\ ${ }^{1}$ Center for Spatial Information Science and Sustainable Development Applications - (rli, lvda, liusjtj, chengyuan_1994, ganghai, \\ xhtong)@tongji.edu.cn,543689277@qq.com \\ ${ }^{2}$ College of Surveying and Geo-Informatics, Tongji University, 1239 Siping Road, Shanghai, 200092, China
}

\section{Commission III, CHGCS III/9}

KEY WORDS: Ice Shelf, 3D Rift Model, Iceberg Calving, Antarctica

\begin{abstract}
:
This paper presents a systematic fracturing study of the Filchner-Ronne Ice Shelf(FRIS) in Antarctica based on multisource data dating back to 1973. Two fracture maps of FRIS were extracted from Landsat-8 OLI images of 2014-2015 and MODIS mosaic of Antarctica (MOA) 2008-2009. The evolution pattern and temporal change of two crucial rifts, Rifts T1 and T2 are analysed for their similarities with the Grand Chasm, which directly induced the previous major calving event of Filchner Ice Shelf(FIS) in 1986. The depth temporal change of Rift T2 was also analysed based on ICESat altimetry data and DEMs reconstructed from ZY-3 and WV-2 stereo images. 3D parameters were also extracted and analysed from DEMs, including rift depth, walls, mélange surface roughness, and mélange thickness. In total, 582 new fractures were extracted from 2004 to 2009 and another 752 from 2008 to 2015. Rifts T1 and T2 showed high activeness, which experienced a rapid growth of $82 \%$ and reached $\sim 50 \mathrm{~km}$ in length. Based on all the observations of fracture and rift activity, some regions of ice shelf front in RIS and FIS show some important characteristics that can be related back to the previous calving events.
\end{abstract}

\section{INTRODUCTION}

Ice shelves can buttress the Antarctic ice sheet and their existence has resistance on ice sheet mass loss. Mass loss from ice sheet have two pathways of iceberg calving and basal melting of ice shelves and they result in a similar amount mass loss (Depoorter et al., 2013; Paolo et al., 2015; Rignot et al., 2013). Rifts are ice shelf fractures with visible opening and penetrated the whole ice shelf (Joughin and MacAyeal, 2005; Walker et al., 2013). In the process of iceberg calving, fractures play an important role. Especially rifts are precursor of calving events and their distribution and evolution pattern greatly influence the calving frequency and iceberg size (Glasser et al., 2009; Joughin and MacAyeal, 2005). To investigate the rifts evolution pattern and their relationship with iceberg calving, this paper presents a systematic study of rifts including fracture mapping, rift 3D reconstruction and the relationship between rift evolution pattern and iceberg calving parameters. This work would contribute to studying and monitoring the stability of ice shelves.

\section{STUDY AREA \& BACKGROUND}

FRIS is the second largest ice shelves in Antarctica, which consists of two composite ice shelves, Ronne Ice Shelf (RIS) and Filchner Ice Shelf(FIS). The last major calving event in FIS and RIS occurred respectively in mid-April of 1986 and from 1998 to 2000.

Different categories of rifts own different origins and evolution patterns and will have impacts on ice shelf calving. Traverse rifts determine the calving range and the frequency of calving events. Marginal rifts can detach ice shelf front from grounded ice of ice sheet. Longitudinal rifts only appear in ice shelf front and calving would take place when traverse rifts propagate to touch longitudinal rifts.

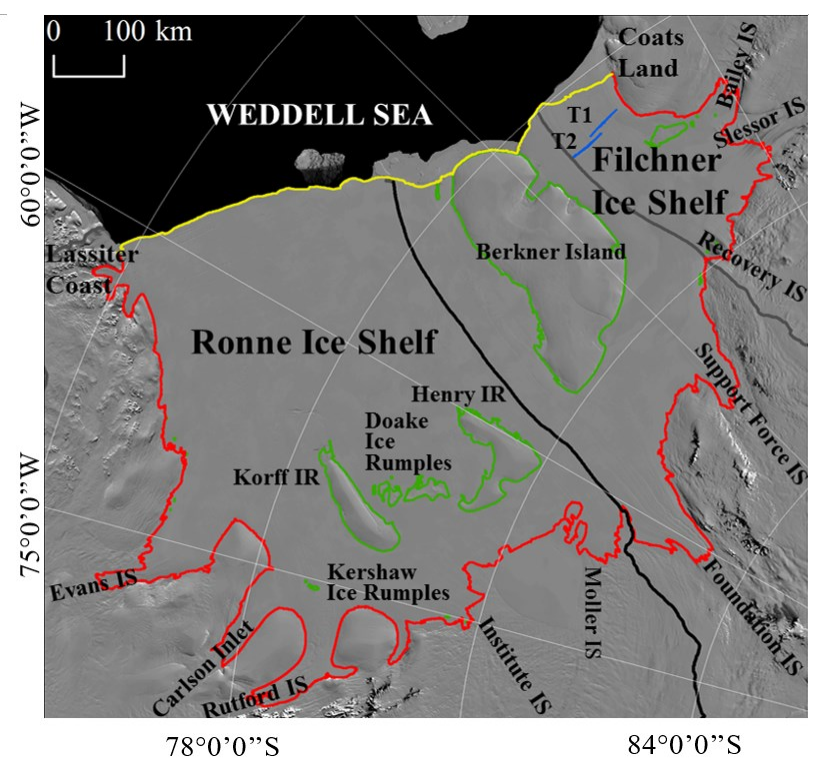

Figure 1. Study area of the Filchner-Ronne Ice Shelf in Antarctica: the ice shelf boundary is represented by grounding line (red lines) and ice rises (green lines) adopted from Depoorter et al. (Depoorter et al., 2013), and the ice shelf front (yellow line) is taken from MOA coastline data (2008-2009)

(Haran et al., 2014); Rift T1 and Rift T2 (blue lines) in the Filchner Ice Shelf; and a background image from the MOA mosaic of 2008 - 2009 (Haran et al., 2014). 


\section{DATA}

Three datasets from different satellite sensors ranging from 1973 to 2018 are used in this study. The first dataset is optical images. Landsat and ASTER images collected during 1973 to 2018 are used for two-dimensional fracture mapping, extraction and measurement of rifts. Landsat images include Landsat-1/2/3 MSS L1GT, Landsat-4/5 TM L1GT, Landsat-7 ETM+ L1GT and Landsat-8 OLI L1GT images. ZY-3 and WV-1/2 stereo images are used to reconstruct the three-dimensional information of Rift $\mathrm{T} 1$ and $\mathrm{T} 2$. Zi Yuan-3 (ZY-3) is a Chinese high-resolution stereoscopic Earth Observation Program with a resolution of 2.1 $\mathrm{m} \sim 3.6 \mathrm{~m}$. The ZY-3 dataset was acquired in a quasi-real-time mode on February 28, 2014, in which the fore and nadir images were taken within a time period of $\sim 30$ seconds. An accuracy of $10.8 \mathrm{~m}$ (horizontal) and $6.1 \mathrm{~m}$ (vertical) can be achieved without ground control points (GCPs) (Tang et al., 2015; Tong et al., 2015). Two pairs of WV-2 panchromatic along-track stereo images were provided by DigitalGlobe which were taken during 2012 and 2016 and cover the eastern part of Rift T2. The nominal geolocation accuracy without using GCPs was reported to be 2.3 $\mathrm{m}$ (horizontal) and $2.2 \mathrm{~m}$ (vertical) (Toutin et al., 2012).The second dataset is SAR images. Envisat ASAR and Sentinel-1A EW GRDF data are used for measuring the length and width of Rift T1 \& T2 when optical images are not available. The third dataset is two tracks of ICESat GLAS points from 2003 to 2008, which are used to analyse the temporal change of Rift T2's depth. The ICESat data product has an overall vertical accuracy of $14 \mathrm{~cm}(5$ $\mathrm{cm}$ in flat areas) (Schutz et al., 2005; Shuman et al., 2006). The data have been applied to global and regional mass balance estimations of AIS and the Greenland Ice Sheet (GIS) (Babonis et al., 2016; Ewert et al., 2012; Sandberg Sørensen et al., 2011). Fracture features of FRIS extracted by Hulbe et al. (Hulbe et al., 2010) from MOA 2003 and 2004 are also used to compared with fracture extracted in this study, which has a geolocation accuracy better than one pixel (Scambos et al., 2007).

\section{METHODOLOGY}

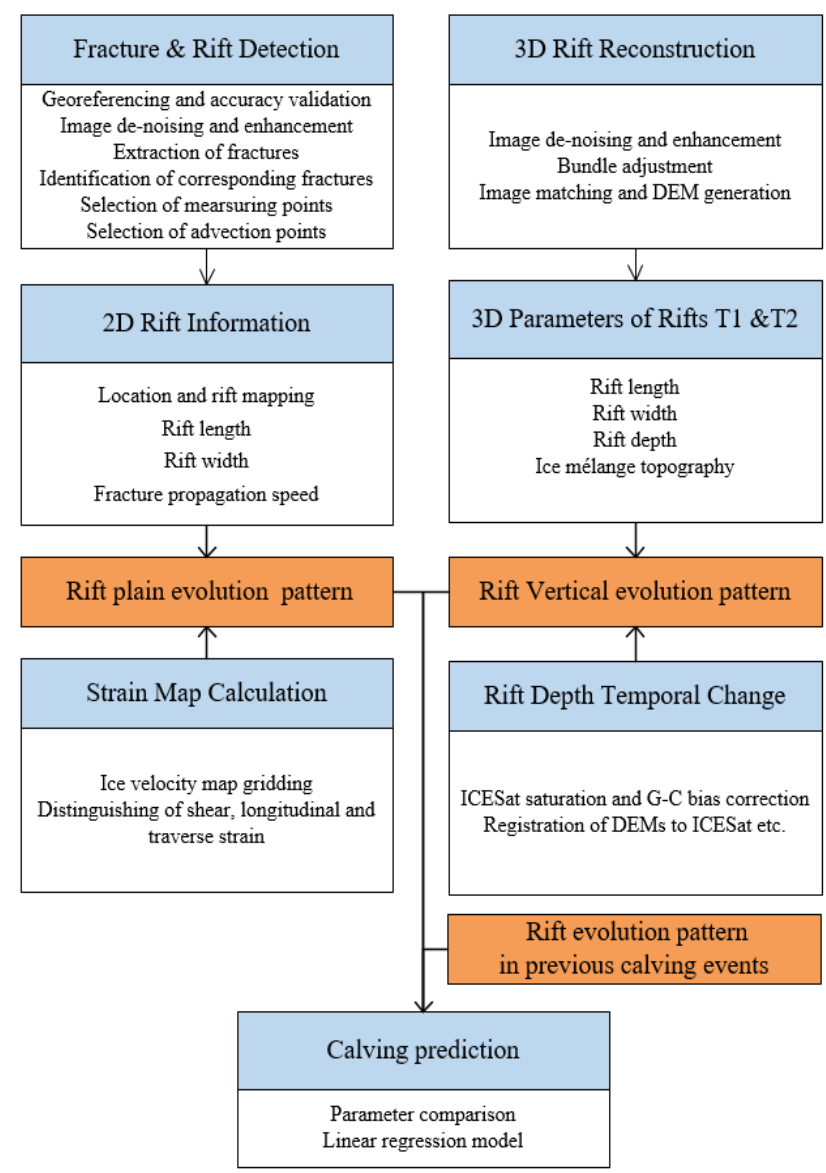

Figure 2. Framework of systematic fracture mapping and analysis of Antarctic ice shelves

As described in Figure 2, a framework for processing long term satellite observations, rift evolution pattern and prediction for calving events has been developed. First, a 2D mapping of fractures of the entire ice shelf was carried out using optical and SAR images to build a time series of observations. Then the temporal change of length and width of rifts are generated based on these observations. Ice shelf strain is the main factor that directly drives the appearance and propagation of ice shelf rifts. Longitudinal, traverse and marginal rifts are mainly influenced by traverse, longitudinal and shear strain respectively so three maps of traverse, longitudinal and shear strain of FRIS are generated from ice flow velocity map. According to rifts' length and width temporal change and ice shelf strain map, rift plain evolution pattern are analysed. Second, high-resolution stereo satellite images are processed to generate DEMs of large rifts and 3D parameters are generated from DEMs, including rift flank elevation, rift width, rift depth, ice mélange top elevation, ice mélange top roughness and rift flank roughness. Depth data are derived and processed from DEMs and ICESat altimetry data. Then the depth temporal change of Rift T2 are analysed. Finally, a comparison between rift evolution pattern in this calving cycle with the previous calving event and a linear regression analysis is conducted to predict the next calving event.

\subsection{Fracture \& rift mapping}

A series of filters, including median filter, Wallis adaptive filtering and contrast limited adaptive histogram equalization (CLAHE), were applied to enhance SAR images and optical images. These processing techniques are necessary for both automatic and manual fracture extraction and comparison. Considering the automation of Antarctic surface feature 
extraction is not mutual enough, a manual extraction of the fracture features was used in this study. A fracture can be measured at two tips and a number of supporting points in between. In this study the tip points are localized using the technique from Walker et al. (Walker et al., 2013); a supporting point is defined and measured at the distinct location that separates two approximately straight fracture segments.

When two sets of fracture features from different times are extracted, a pair of corresponding fractures can be established if the same rift or crevasse is identified by comparing its location, size, shape, and other distinctive characteristics. And then its propagation pattern and speed can be derived. The fracture propagation speed is estimated by the distances measured between the corresponding points of the two fractures are achieved. A validation of the estimated fracture propagation speed can be carried out by a comparison with existing ice velocity maps.

\subsection{DEM generation \& validation}

Due to the low-contrast and flat topography of the ice shelf, image denoising and enhancement procedures should be employed beforehand to boost contrast gradient and depress noise. In this research, haze removement, contrast limited adaptive histogram equalization/CLAHE (Zuiderveld, 1994), histogram matching, wiener filter (Lim, 1990) and wallis adaptive filter (Fahnestock and Schowengerdt, 1983), had been sequentially applied to the stereo imagery.

Stereopair images of $\mathrm{ZY}-3$ were then processed by bundle adjustment (BA) with affine compensation models to remove the relative geometric disparities and a final DEM product was generated at a resolution of $5 \mathrm{~m}$ by $5 \mathrm{~m}$.

The WV-2 DEM reconstruction followed as much the same as the ZY-3 DEM generation procedures with the only difference being in the BA in which shift compensation model was used instead which is better suited for WV-2 panchromatic scenes. Gridding space was set to be $1 \mathrm{~m}$.

These generated DEMs can help us to gain insight into the depth and width of the rift, the shape of the ice mélange and more importantly the distribution of the above parameters with respect to their relative position within the rift. These parameters can be well incorporated into ice-sheet models to better compensate for rifts.

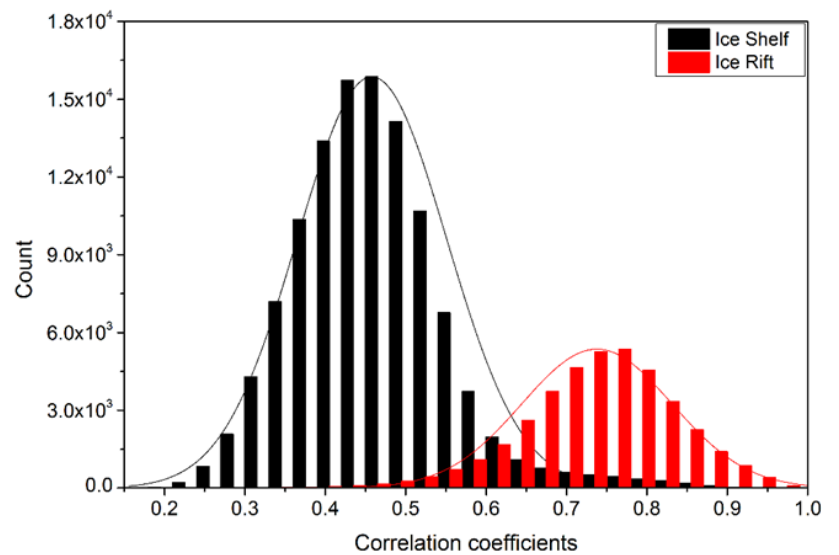

Figure 3. Histogram of correlation coefficients of matched points for the ZY-3 DEM: points inside Rift T2 (red) and points on the ice shelf (black)

The absolute accuracy of the ZY-3 ground points is $\sim 10 \mathrm{~m}$ (horizontal) and $\sim 6 \mathrm{~m}$ (vertical), which depicts the overall location accuracy of the ZY-3 DEM in the ground coordinate system (Tang et al., 2015; Wang et al., 2014). The relative accuracy depends on the quality of the matched points and two assessing metrics were adopted ( $\mathrm{Li}, 1998 ; \mathrm{Li}$ et al., 2017). The first metric is correlation coefficients calculated using a window of 25 by 25 pixels. Figure 3 shows that the correlation coefficients of the points matched inside rift $\mathrm{T} 2$ (floor and walls) have a mean value of 0.72 and is significantly higher than that of 0.46 on the ice shelf surface because of the higher level of image texture of rift mélange on the floor. The second metric is image location differences (residuals) between automatic and manually matched points. Within the study area the matched points may be distributed unevenly. A grid is defined and overlaid on the matched points. In each grid cell one matched point is selected and compared with its manually matched point. A total of 135 such points were used to perform the validation. The result shows that the relatively flat ice shelf surface on both sides of rift $\mathrm{T} 2$ has a mean residual of 0.70 pixels and that inside the rift is 0.77 pixels, which validates the matching reliability.

The photogrammetric processing and DEM reconstruction from the WV-2 images follow a similar procedure as that of the ZY-3 images. The DEM grid spacing is set as $1 \mathrm{~m}$. The generated DEMs can be used to estimate a set of rift parameters, including depth, width, shape of the walls, mélange floor topography, and others, for ice shelf stability analysis and improvement of physical models of ice shelves.

\subsection{Strain calculation}

To determine the strain rate of Filchner Ronne Ice Shelf, ice flow velocity products from MEaSUREs are utilized (Mouginot et al., 2017). The velocity in $\mathrm{x}$ and $\mathrm{y}$ direction are gridded to $1 \mathrm{~km}$ spacing, and then take the ice flow direction into consideration, the strain rates related to ice flow are

$$
\begin{gathered}
\varepsilon_{s}=\left(\varepsilon_{y}-\varepsilon_{x}\right) \sin \alpha \cos \alpha+\varepsilon_{x y}\left(\cos ^{2} \alpha-\sin ^{2} \alpha\right) \\
\varepsilon_{l}=\varepsilon_{x} \cos ^{2} \alpha+2 \varepsilon_{x y} \sin \alpha \cos \alpha+\varepsilon_{y} \sin ^{2} \alpha \\
\varepsilon_{t}=\varepsilon_{x} \sin ^{2} \alpha-2 \varepsilon_{x y} \sin \alpha \cos \alpha+\varepsilon_{y} \cos ^{2} \alpha
\end{gathered}
$$

Where $\alpha$ is angle that goes counterclockwise from $\mathrm{x}$-axis, $\varepsilon_{s}$ represents for the shear strain rate, $\varepsilon_{l}$ is the longitudinal strain rate and $\varepsilon_{t}$ is the transverse strain rate. $\varepsilon_{x}, \varepsilon_{x y}$ and $\varepsilon_{y}$ are the strain rate along the direction of east, north-east and north (Bindschadler et al., 1996; Han et al., 2016; Nye, 1959).

\section{RESULTS}

First, ice shelf fractures in 2008-2009 \& 2014-2015 in RonneFilchner Ice Shelf was derived and mapped. In total, 582 new fractures were extracted from 2004 to 2009 and another 752 from 2008 to 2015 . Second, fracture propagation speed from 20032004 to 2008-2009 and from 2008-2009 to 2014-2015 in RonneFilchner Ice Shelf was estimated. Third, temporal changes of the width and length of Rift T1 and Rift T2 in Filchner Ice Shelf were estimated. At beginning both $\mathrm{T} 1$ and $\mathrm{T} 2$ show a stable state until abrupt expansion happened. Rift T2 had an abrupt expansion in length in 2006, reaching up to $40 \mathrm{~km}$ long. Rift T1 had an abrupt expansion in 2011 in both length and width reaching up to $50 \mathrm{~km}$ long and $1400 \mathrm{~m}$ wide. After that both T1 and T2 have propagated in a steady rate in both length and width. Finally, three DEMs are generated from ZY-3 images captured in 2014 and WV-2 images in 2012 and 2016. Detailed 3D characteristics of ice shelf surface, rift walls and ice mélange surface are well reconstructed. DEMs along with ICESat data were also used to detect the depth propagation process of Rift T2. The lowest point of both ICESat tracks had an overall trend of descending from 2003 to 2009, which indicates the rift kept deepening in this period. The lowest point heights of ICESat data in 2009 are the same as that of DEMs of 2012, 2014 and 2016, which represents Rift T2 may completely penetrated in 2009 and then the height of rift bottom has kept stable. 


\section{CONCLUSION}

This paper presents the results of a framework of systematic fracture mapping and evolution pattern revealing of ice shelf rifts in Filchner-Ronne Ice Shelf, Antarctica. A two-dimensional mapping of fractures are derived from optical and SAR images. Three-dimensional DEMs of crucial rifts are generated from stereo images. Then various rift parameters temporal change and rift evolution pattern can be analysed from two-dimensional fracture mapping and DEMs. Finally, the relationship between rift propagation process and ice shelf calving events is analysed to further predict next calving pattern.

\section{ACKNOWLEDGEMENTS}

The work was substantially supported by National Key R\&D Program of China (Grant No. 2017YFA0603100) and the Chinese National Natural Science Foundation (41730102).

\section{REFERENCES}

Babonis, G., Csatho, B., Schenk, T., 2016. MASS BALANCE CHANGES AND ICE DYNAMICS OF GREENLAND AND ANTARCTIC ICE SHEETS FROM LASER ALTIMETRY. International Archives of the Photogrammetry, Remote Sensing \& Spatial Information Sciences 41.

Bindschadler, R., Vornberger, P., Blankenship, D., Scambos, T., Jacobel, R., 1996. Surface velocity and mass balance of Ice Streams D and E, West Antarctica. Journal of Glaciology 42, 461-475.

Depoorter, M.A., Bamber, J., Griggs, J., Lenaerts, J., Ligtenberg, S.R., van den Broke, M., Moholdt, G., 2013. Antarctic ice-shelf thickness, ice-shelf mask, and grounding line (datasets used in.

Ewert, H., Groh, A., Dietrich, R., 2012. Volume and mass changes of the Greenland ice sheet inferred from ICESat and GRACE. Journal of Geodynamics 59, 111-123.

Fahnestock, J.D., Schowengerdt, R.A., 1983. Spatially variant contrast enhancement using local range modification. Optical Engineering 22, 223378.

Glasser, N., Kulessa, B., Luckman, A., Jansen, D., King, E.C., Sammonds, P., Scambos, T., Jezek, K., 2009. Surface structure and stability of the Larsen $\mathrm{C}$ ice shelf, Antarctic Peninsula. Journal of Glaciology 55, 400-410.

Han, H., Im, J., Kim, H.-c., 2016. Variations in ice velocities of Pine Island Glacier Ice Shelf evaluated using multispectral image matching of Landsat time series data. Remote Sensing of Environment 186, 358-371.

Haran, T., Bohlander, J., Scambos, T., Painter, T., Fahnestock, M., 2014. MODIS Mosaic of Antarctica 2008-2009 (MOA2009) image map. Boulder, Colorado USA, National Snow and Ice Data Center 10, N5KP8037.

Hulbe, C.L., LeDOUX, C., Cruikshank, K., 2010. Propagation of long fractures in the Ronne Ice Shelf, Antarctica, investigated using a numerical model of fracture propagation. Journal of Glaciology 56, 459-472.
Joughin, I., MacAyeal, D.R., 2005. Calving of large tabular icebergs from ice shelf rift systems. Geophysical research letters 32 .

Li, R., 1998. Potential of high-resolution satellite imagery for national mapping products. Photogrammetric Engineering and Remote Sensing 64, 1165-1170.

Li, R., Ye, W., Qiao, G., Tong, X., Liu, S., Kong, F., Ma, X., 2017. A New Analytical Method for Estimating Antarctic Ice Flow in the 1960s From Historical Optical Satellite Imagery. IEEE Transactions on Geoscience and Remote Sensing 55, 2771 2785.

Lim, J.S., 1990. Two-dimensional signal and image processing. Englewood Cliffs, NJ, Prentice Hall, 1990, 710 p.

Mouginot, J., Rignot, E., Scheuchl, B., Millan, R., 2017. Comprehensive annual ice sheet velocity mapping using Landsat-8, Sentinel-1, and RADARSAT-2 data. Remote Sensing $9,364$.

Nye, J., 1959. A method of determining the strain-rate tensor at the surface of a glacier. Journal of Glaciology 3, 409-419.

Paolo, F.S., Fricker, H.A., Padman, L., 2015. Volume loss from Antarctic ice shelves is accelerating. Science 348, 327-331.

Rignot, E., Jacobs, S., Mouginot, J., Scheuchl, B., 2013. Ice-shelf melting around Antarctica. Science 341, 266-270.

Sandberg Sørensen, L., Simonsen, S.B., Nielsen, K., LucasPicher, P., Spada, G., Adalgeirsdottir, G., Forsberg, R., Hvidberg, C., 2011. Mass balance of the Greenland ice sheet (2003-2008) from ICESat data-the impact of interpolation, sampling and firn density. The Cryosphere 5, 173-186.

Scambos, T., Haran, T., Fahnestock, M., Painter, T., Bohlander, J., 2007. MODIS-based Mosaic of Antarctica (MOA) data sets: Continent-wide surface morphology and snow grain size. Remote Sensing of Environment 111, 242-257.

Schutz, B., Zwally, H., Shuman, C., Hancock, D., DiMarzio, J., 2005. Overview of the ICESat mission. Geophysical Research Letters 32.

Shuman, C., Zwally, H., Schutz, B., Brenner, A., DiMarzio, J., Suchdeo, V., Fricker, H., 2006. ICESat Antarctic elevation data: Preliminary precision and accuracy assessment. Geophysical Research Letters 33.

Tang, X., Zhou, P., Zhang, G., Wang, X., Jiang, Y., Guo, L., Liu, S., 2015. Verification of ZY-3 satellite imagery geometric accuracy without ground control points. IEEE Geoscience and Remote Sensing Letters 12, 2100-2104.

Tong, X., Li, L., Liu, S., Xu, Y., Ye, Z., Jin, Y., Wang, F., Xie, H., 2015. Detection and estimation of ZY-3 three-line array image distortions caused by attitude oscillation. ISPRS journal of photogrammetry and remote sensing 101, 291-309.

Toutin, T., Schmitt, C., Wang, H., 2012. Impact of no GCP on elevation extraction from WorldView stereo data. ISPRS journal of photogrammetry and remote sensing 72, 73-79.

Walker, C., Bassis, J., Fricker, H., Czerwinski, R., 2013. Structural and environmental controls on Antarctic ice shelf rift 
propagation inferred from satellite monitoring. Journal of Geophysical Research: Earth Surface 118, 2354-2364.

Wang, T., Zhang, G., Li, D., Tang, X., Jiang, Y., Pan, H., Zhu, X., Fang, C., 2014. Geometric accuracy validation for ZY-3 satellite imagery. IEEE Geoscience and Remote Sensing Letters $11,1168-1171$.

Zuiderveld, K., 1994. Contrast limited adaptive histogram equalization. Graphics gems, 474-485. 